\title{
Prevention is key to halting the global silent killer - cancer
}

\author{
Diane Blonski and Waqas Ullah Khan
}

University of Toronto

Cancer- cáncer (Spanish) - rak (polish), - kanker (dutch), 癌症 (Chinese simplified) - is a disease with no boundaries. Although cancer is often thought to only affect individuals from the developed world, over half of the 12.4 million new cases and two-thirds of cancer-associated deaths occur in developing countries ${ }^{1}$. Strikingly, this disease kills more individuals than AIDS, tuberculosis and malaria combined yet is often ignored in major global health initiatives ${ }^{2,3}$. The World Health Organization (WHO) has attributed this neglect to many misconceptions including, 1) cancer only affects developed nations, 2) cancer prevention is too expensive, 3) cancer is not preventable, 4) cancer affects primarily men and 5) cancer affects only old people ${ }^{3}$. In recent years, programs have been implemented to target cancer prevention. In 2007, the Global Alliance for Chronic Disease (GACD) was created with cancer being one of its top priorities ${ }^{4}$.

It is estimated that by 2020 , there will be approximately 9.25 and 5.75 million new annual cancer cases occurring in developing and developed countries, respectively ${ }^{5}$. With a lack of global health initiatives to prevent cancer in developing countries, a disproportionate increase in the rate of incidence is expected. Moreover, developed countries may experience greater success in cancer prevention as a result of increased policies and strategies

for prevention ${ }^{6}$.

Many forms of cancer are ultimately preventable; however, it is still one of the leading causes of morbidity and mortality worldwide ${ }^{7}$. Estimates indicate that $40 \%$ of cancer deaths can be prevented ${ }^{6}$. Lung cancer, for example, has an incidence rate of 23 per 100000 , accounting for 1.61 million new cases diagnosed worldwide in 2008 alone, and has a mortality ratio of 19 per $100000^{5,8,9}$. Although cancer mortality is expected to increase $104 \%$ worldwide by 2020 , developing countries will bear the brunt of countries will bear the brunt of this burden with an increase of 144-181\%. In contrast, rates in developed nations are predicted to rise only $25 \%{ }^{10}$. One explanation for this uneven distribution of cancer mortality rates is that developed nations have made progress in the prevention of cervical, lung, and liver cancer. Conversely, the incidence of these cancers continues to rise in developing countries $^{5}$. For example, although the risk factors are similar between developed and developing nations, $80 \%$ of new cervical cancer cases will occur in low-income countries ${ }^{5}$.

From a global health perspective, the key to reducing cancer incidence and mortality is through primary prevention which includes the elimination of cancer-associated risk factors such as infection, smoking, inactivity, and poor diet ${ }^{1,5,11}$. Recently, many large-scale programmes focusing on primary and secondary cancer prevention have been initiated and are gaining momentum in developing countries ${ }^{5,6,12}$. Primary prevention strategies include tobacco control, immunization, treatment of infections, and healthy lifestyle promotion ${ }^{5,13,14}$. It is estimated that $25-30 \%$ of cancer cases in developed countries are related to smoking. Cigarette smoking is a fairly recent phenomenon in developing countries, although it is expected to drastically increase within the coming decade if anti-smoking campaigns are not implemented immediately ${ }^{1}$. Strikingly, by 2030 it is estimated that $70 \%$ of tobacco-related deaths will occur in developing countries, further straining their already underfunded health-care systems ${ }^{12}$. Internationally, tobacco-related deaths account for $60 \%$ of avoidable cancer deaths ${ }^{6}$. An example of a county successfully implementing an anti-smoking campaign is Brazil. Together with the help of the WHO, Brazil has experienced a 13\% national reduction in smoking since 1989 . China is another country integrating cancer prevention into its healthcare stratagem. Currently, liver cancer attributed to the high prevalence of Hepatitis B infection is the leading cancer morbidity in China. As a result, China's goal is to eradicate Hepatitis B infection in children by immunizing newborns within 24 hours of birth to prevent an infected mother from transmitting the disease to her child ${ }^{6}$.

When risk factors cannot be eradicated, secondary prevention strategies can be implemented to reduce cancer risk. Measures that can reduce the growing incidence of cancer in developed nations include initiatives such as annual pap smear tests for women to detect precancerous lesions relating to cervical cancer as well as immunization of Hepatitis $C$ patients against Hepatitis $\mathrm{A} / \mathrm{B}^{1,14}$. Rudimentary, but effective, secondary prevention measures in developing nations such as visual 
inspection with acetic acid programs to detect precancerous cervical lesions have also been successfully implemented in Kenya and Thailand ${ }^{12}$. Primary and secondary prevention programs have shown promise in decreasing cancer morbidity and mortality, but further development and tailoring of programs are still required.

The extension of preventative measures to people at risk of developing cancer is an urgent health priority. With cancer incidence and mortality rates increasing in the developing world, a concerted global effort is required to reduce the burden of illness in low- and middle-income countries. Prevention is often seen as the key to combating cancer since it results in the best health outcomes and is the most costeffective strategy. This is especially evident in preventable cancers such as lung, cervical and liver ${ }^{3,6,14}$. In recent years, the international health community has united to confront the cancer pandemic by creating international bodies such as $\mathrm{GACD}^{4}$. In order for the momentum to continue, it is important that regional, national, and international organizations further enhance their collaborative partnerships. Although battling cancer can be complex, governments must continue to stress the importance of prevention to reduce incidence and mortality rates in both developed and developing countries.

\section{References}

1. Boyle P, Levin B. World Cancer Report 2008. Lyon: International Agency for Research on Cancer;2008.

2. Beaulieu M, Bloom D, R. B, Stein R. Breakaway: the global burden of cancer - challenges and opportunities $>A$ report from the Economist Intelligence Unit January 25, 20112009.

3. Jones LA, Chilton JA, Hajek RA, Iammarino NK, Laufman L. Between and within: international perspectives on cancer and health disparities. J Clin Oncol. May 10 2006;24(14):2204-2208.

4. GACD. Global Alliance for Chronic Disease. http://www.ga-cd.org/who.php. Accessed January 26, 2011, 2011.

5. Kanavos P. The rising burden of cancer in the developing world. Annals of Oncology. 2006;17(Supplement 8):viii15viii23.

6. WHO. The World Health Organization's Fight Against Cancer Strategies that Prevent, Cure and Care. Geneva2007:1-25.

7. Seffrin JR. Cancer control as a human right. Lancet Oncol. May 2008;9(5):409-411.

8. Ferlay J, Shin HR, Bray F, Forman D. GLOBOCAN 2008, Cancer Incidence and Mortality Worldwide: IARC CancerBase CancerBase No. 10. Lyon, France: International Agency for Research on Cancer;2010.

9. Jemal A, Thun MJ, Ries LA, et al. Annual report to the nation on the status of cancer, 1975-2005, featuring trends in lung cancer, tobacco use, and tobacco control. J Natl Cancer Inst. Dec 3 2008;100(23):1672-1694.
10. Rastogi T, Hildesheim A, Sinha R. Opportunities for cancer epidemiology in developing countries. Nat Rev Cancer. Nov 2004;4(11):909-917.

11. Farmer P, Frenk J, Knaul FM, et al. Expansion of cancer care and control in countries of low and middle income: a call to action. Lancet. Oct 2 2010;376(9747):1186-1193.

12. Mellstedt H. Cancer initiatives in developing countries. Ann Oncol. Jun 2006;17 Suppl 8:viii24-viii31.

13. Garcia M, Jemal A, Ward EM, et al. Global Cancer Facts \& Figures 2007. Atlanta, GA: American Cancer Society;2007.

14. Thun MJ, DeLancey JO, Center MM, Jemal A, Ward EM. The global burden of cancer: priorities for prevention. Carcinogenesis. Jan 2010;31(1):100-110.

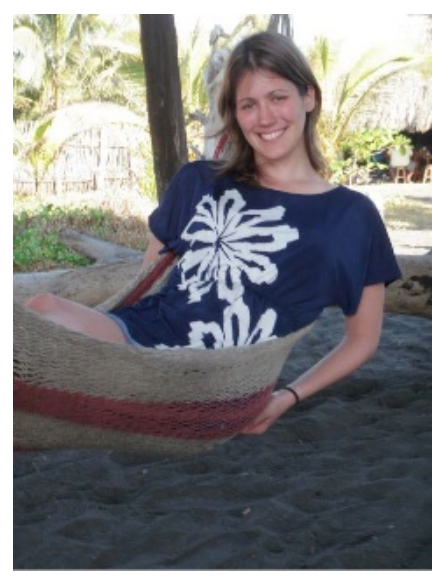

Author Profiles

Diane Blonski received her MSc in Human Health and Nutritional Science from the University of Guelph. She is currently working as a Clinical Research Coordinator at The Hospital for Sick Children focusing on rare liver diseases. She previously received her BSc from the University of Guelph in Biological Science. In September she will be pursuing a Master of Science in Physical Therapy at the University of Toronto. Her main research interests include rehabilitation medicine, nutrition, health-related quality of life, child health and medicine.

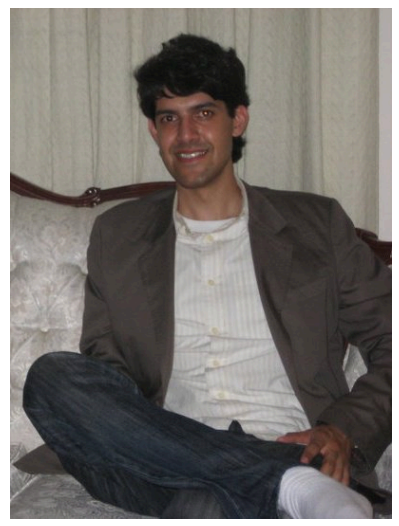

Waqas Ullah Khan recently completed his MSc from the Department of Nutritional Science at the University of Toronto where he also received his Honours BSc. $\mathrm{He}$ is currently working as a Clinical Research Associate at The Hospital for Sick Children where his research focus is on pediatric nutrition from a global health perspective and the efficacy of various minimally invasive otolaryngology and interventional radiology-based procedures. His main research interests include child health, nutrition, and global health. 